\title{
(1)
}

\begin{tabular}{||l||c|c||}
\hline Received 06.07.2021 & & JOTS \\
$5 / 2$ \\
Accepted 19.07.2021 \\
\hline Published 24.07.2021 & Review & $2021: 446-450$ \\
\hline
\end{tabular}

\section{Zieme, P. Uigurorum veterum fragmenta minora, Turnhout (Belgium): Brepols Publishers, 2020, pp. $392+$ 155 Colour ill., ISBN: 978-2-503-59304-3}

\author{
Erdem UçAR* \\ Friedrich-Schiller-Universität Jena (Jena/Germany) \\ E-mail: erdem.ucar@uni-jena.de
}

Uyguristiğin ve Türkolojinin önemli bir siması olan Peter Lothar Zieme (1942- ), İranist W. Sundermann'ın (1935-2012) yönlendirmesiyle Şarkiyat okumaya karar vermiş ve Berlin Humboldt üniversitesi İranistik bölümünde lisans eğitimini tamamladıktan sonra, müteveffa Türkolog G. Hazai'nin Berlin Humboldt üniversitesinde Türkoloji bölümünü güçlendirme çabalarının neticesinde çalışma sahasını Türkolojiye kaydırmış ve Hazai'nin danışmanlığında 1965'te Manihey harfli Uygurca yazmaların imlâ özellikleri hakkında bir doktora tezi hazırlamıștır. Erken dönem Uyguristlerden olan A. von Gabain'in doğrudan öğrencisi olmamasına rağmen, Zieme onunla vefatına değin yakın ilişki içerisinde olmuş ve kendisinden istifade etme imkânı bulmuştur (Ölmez \& Raschmann, 2002: 9-13).

Zieme, Turfanforschung çalışma grubu ile yıllardır irtibatını kesmemesi sayesinde Berlin'deki pek çok Uygurca yazmanın neşrini kendi başına veya meslektaşları ile beraber neşretmeyi başarmıştır. Zieme, sadece Almanya'daki Uygurca parçaların neşriyle değil, ayrıca Japonya, Rusya, Çin, vs. gibi Uygurca yazmaların bulunduğu dünyanın muhtelif kütüphanelerinde muhafaza edilen metinlerin neşrini de kendi başına veya meslektaşlarıyla beraber hazırlamıştır. Uyguristik sahasının en velut uzmanlarından biri olan Zieme bugün hayatını Berlin'de sürdürmektedir. S.-Ch. Raschmann tarafından hazırlanan Zieme'nin

\footnotetext{
ORCID ID: 0000-0002-0039-9619.
} 


\section{1)}

güncel yayın listesine Berlin Brandenburg Bilimler Akademisi'ne bağlı olarak çalışan Turfanforschung grubunun internet sayfasından ulaşılabilir.

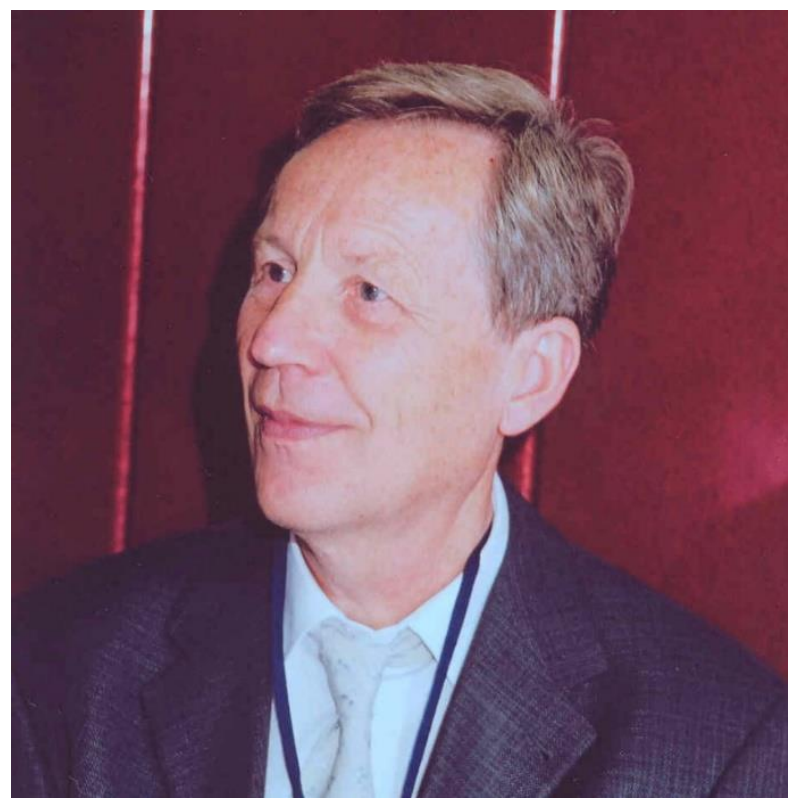

Prof. Dr. Peter Zieme (2004)

Geçen asrın başında Almanlar Doğu Türkistan'a çeşitli keşifgezileri yapmış ve Şark dünyasına ait birçok orijinal yazmayı Almanya'ya getirerek bunları koruma altına almıştır. Bu keşifgezilerinde pek çok Eski Türkçe malzeme de elde edilmiştir. Bu malzemenin işlenmesi için W. Bang ve talebeleri Türkische Turfantexte başlıklı bir neşir dizisi başlatmış ve II. Dünya savaşına kadar bu seri düzenli olarak neşredilmiştir. Savaş sonrasında neşir serisi Berliner Turfantexte ismi altında hayatına devam etmiştir. Şimdiye kadar bu seride 47 cilt çıkmıştır. Bu 47 cildin 26 tanesi Eski Türk dili ve kültürü ile ilgili olup geri kalan 21 cilt Asya'daki diğer dillerle (Çince, Soğdça, Moğolca, vs.) ilgilidir.

Burada kısaca tanıtımını yapacağım eser, Berliner Turfantexte serisinin son cildi olan 47. cilt hakkında olacaktır. Eser, Kaynakça (9-31), Kısaltmalar (33-36) ve Uygurca Parçaların Listesi (37-46) ile başlamaktadır. Kitaptaki yazılar konuları bakımından dört gruba ayrılmıştır: 1. Hristiyan çevreye ait yazılar (2 adet); 2. Manihey çevreye ait yazılar (8 adet); 3. Burhancı çevreye ait yazılar (30 adet); 4. Çeşitli yazılar (13 adet). Buradaki tasnif aslında yazarın Budizmden Maniheizme ve Hristiyanlığa kadar uzanan Uyguristik sahasındaki geniş çalışma sahasını da göstermektedir. 


\section{J(e)}

Kitapta Zieme'nin Uygurca kelimeler ve kavramlar hakkındaki çeşitli yazıları bulunmaktadır. Yazıların büyük bir kısmı daha önce "academia.edu" adresindeki dijital platformda yayımlanmıştır, ancak 10, 26, 35, 36, 37, 45, 51 ve 52 numaralı yazılar ilk kez elimizdeki kitapta gün yüzüne çıkmıştır. Kitaptaki yazıların başlıkları şu şekildedir:

Christiana (49-59)

1. Ein altuigurisches Fragment eines Marientextes aus der Ōtani-Sammlung der Bibliothek der Ryūkoku-Universität (49-50); 2. Corrigenda et addenda zu meinen Editionen türkischer christlicher Texte (51-59).

\section{Manichaica (63-86)}

3. Ist agduk ein Lehnwort aus dem Mitteliranischen? (63-66); 4. Zum Pferdenamen arkun (67-69); 5. Gab es altuigurisch lom? (71-72); 6. Altuigurische Belege für Adam und Eva (73-74); 7. Altuigurisch tonkõ (75-76); 8. Neue Fragmente zum altuigurischen Xvāstvānīft (77-80); 9. Eine Notiz zu Manis vier Vorläufern (81-83); 10. Altuigurisch äšidütči (85-86).

\section{Buddhica (89-297)}

11. "Auf dem Weg des Windes geht er, auf dem Weg des Wassers kommt er". Zur Interpretation zweier altuigurischer buddhistischer Fragmente (89-95); 12. Altuigurischer Lobpreis auf Maitreya in Versen, die in der Anrufung, die Nöte des Uigurischen Reichs zu lindern, kulminieren (97-103); 13. Altuigurisches Fragment aus einer Tempelbeschreibung (105-106); 14. Brahmanen und die Vier Edlen Wahrheiten in altuigurischer Überlieferung (107-114); 15. Buddhas Stimme und abhedyaprasāda. Zwei Texte auf einem altuigurischen Blatt (115-119); 16. Buddhistische Anschauungen über den Körper und die Leere nach einer altuigurischen Handschrift (121-130); 17. Das Bild vom "Mond im Wasser (shuiyue 水月)" in altuigurischen Texten (131-133); 18. Ein fast vollständiger altuigurischer Opfer-Segen (135-142); 19. Ein Fragment der Jñānolkadhāraṇī in chinesischer Schrift nebst uigurischer Umschrift (143-148); 20. Kanakavarṇa und Kāñcanaprabhā in einer altuigurischen Version (149-154); 21. Lakșmī \& Alakṣmī oder Glück und Unglück sind Schwestern nach einer altuigurischen Version aus Dunhuang (155-158); 22. Nanda und Upananda in einem altuigurischen Text (159166); 23. Neues zur altuigurischen Sitātapatrādhāraṇī (165-166); 24. Notizen zum altuigurischen Chan-Gedicht "Zwölf Stunden" (167-176); 25. Notizen zur “Jadeherrin" (177-182); 26. Eine altuigurische Abschrift des Säkiz yükmäk yaruk sudur aus Kumtura (183); 27. Premières notes sur quelques fragments vieuxouïgours de Paul Pelliot (185-200); 28. Rings um die Juweleninsel. Notizen zu altuigurischen buddhistischen Kommentartexten (201-205); 29. Vom Spruch zum 


\section{ग(৫)}

Mantra (207-209); 30. Zwischen Thron und Misthaufen. Die Geschichte von Anāthapiṇ̣̂ika in einer altuigurischen Blockdruck-Version (211-216); 31. Ein Kommentar zum altuigurischen Schwitzbadsūtra (217-224); 32. Eine altuigurische Übersetzung von Versen aus der Mahāvibhāṣā (225-232); 33. Eine weitere Handschrift einer altuigurischen Übersetzung des Buddhāvatamsakasūtra (233234); 34. anuloma und pratiloma im altuigurischen Buddhismus (235-238); 35. Ein weiteres Fragment der Daśakarmapathāvadānamālā aus Yargol (Yarxoto) (239240); 36. Ein übersehenes Fragment des altuigurischen VimalakīrtinirdeśaKommentars (241-242); 37. Ein weiteres Blatt der Sattvaușadha-Handschrift (243); 38. Kurze Notiz zu den altuigurischen Vajracchedikā-Kommentaren des Meister Fu (245-246); 39. Zur altuigurischen Blockdruckversion von Meister Fus Vajracchedikā-Kommentar in Versen (academia.edu August 2016) (247-252); 40. Drei altuigurische Triratna-Vergleiche und ein Lobpreis (253-258); 41. Notizen zur “Altuigurischen Dichtung" von Abdurishid Yakup (259-297).

Varia (301-334)

42. Eine Ergänzung zur qars-Liste (MOTH Nr. 34) (301-302); 43. Gibt es altuigurisch artčõ? (303-304); 44. Zur altuigurischen Zwiebel (305-306); 45. Altuigurisch kärägü und kärägä "Scherengitterjurte" (307-308); 46. Altuigurisch "geschwätzig" und ähnliche Bildungen (309-310); 47. Zu altuigurisch azaglašmak (311-312); 48. Altuigurisch yamalok (313-314); 49. Altuigurisch čomak (315-317); 50. Altuigurisch tüzügsüz (319-322); 51. Lasen die alten Uiguren Vorderseiten chinesischer Buchrollen? (323-323); 52. A note on forerunners of Kõrgõz küröš- and küröšūčü (327-328); 53. Altuigurisch tuhčik (329-331); 54. Altuigurisch kuğursak (333-334).

Eserin sonunda yazılardaki kelimelerin dizini (337-370) ve genel bir dizin (371-392) bulunmaktadir.

Zieme, Eski Uygurca sahasına değerli katkılar sunan bir filologdur. Talebeleri tarafından kendisinin Uyguristik sahasındaki seçme yazıları daha önce bir kitapta toplanmıştır (2009). Elimizdeki Berliner Turfantexte serisinin 47. cildinde yazar hem yazılarını bir araya toplamış hem de böylece birçok Eski Uygurca parçanın neşrini gerçekleştirmiştir. Uyguristik bu sayede Eski Uygurca parçaların yeni neşrine ve parçalarla ilgili birçok Eski Uygurca kelime ve kavramın izahına kavuşmuştur. Yazarı tebrik ederken, kendisine sağlık dolu nice yillar dilerim.

\section{Kaynakça}

Ölmez, M. \& Raschmann, S.-Ch. (2002). Splitter aus der Gegend von Turfan, Festschrift für Peter Zieme anläßlich seines 60. Geburtstags. İstanbul-Berlin. 


\section{(주)}

Zieme, P. (2009). Fragmenta Buddhica Uigurica, ausgewählte Schriften von Peter Zieme. Hrsg. von Raschmann, S.-Ch. \& Wilkens, J., Klaus Schwarz Verlag. 